\title{
AS NOVAS TECNOLOGIAS NO PROCESSO DE ENSINO APRENDIZAGEM
}

\author{
Maria Lucineide Dioginis, José Jailton da Cunha, Fernando Henrique Neves, Wiilson Cristovam
}

Universidade San Carlos - USC, Programa de Pós-Graduação em Ciências da Educação, Assunção, Paraguai. E-mail: postgrado@sancarlos.edu.py

\section{RESUMO}

O presente artigo trata da importância da utilização das Novas Tecnologias no ensino. Tem como objetivo averiguar a contribuição de tais tecnologias para o aprendizado. A tecnologia é elemento integrante do cotidiano dos estudantes e, por isso, é fundamental sua utilização no processo de ensino aprendizagem. Neste estudo constatou-se gradual resultado de aprendizagem e disto infere-se que é importante sua utilização para o ensino de qualidade, uma vez que pouco se investiu no sistema educacional e sua infraestrutura para o seu desenvolvimento qualitativo. A pesquisa situa-se na área da educação, é de abordagem qualitativa com eixo epistemológico histórico crítico-dialético, foi desenvolvida na Escola Pública do Estado de São Paulo. Contribuirá para a reflexão crítica dos professores, tendo em vista a necessária superação da exclusão digital. É, igualmente, uma análise da pedagogia presente em escola pública que não considera as tecnologias com perspectivas de uma educação de qualidade.

Palavras-chave: Tecnologias. Mídias. Ensino. Aprendizagem. Educação

\section{NEW TECHNOLOGIES IN EDUCATION PROCESS LEARNING}

\begin{abstract}
This article deals with the importance of using new technologies in education. It aims to investigate the contribution of these technologies for learning. Technology is an integral element of the daily lives of students, and therefore, it is essential its use in teaching and learning process. In this study we found a gradual learning outcome and it is inferred that it is important to use for quality education, since little is invested in education and infrastructure to its qualitative development. The research lies in education, is a qualitative approach with historical epistemological critical- dialectical axis, it was developed in the Public School of São Paulo. Contribute to the critical reflection of teachers, given the necessary overcoming the digital divide. It is also a pedagogy of this analysis in public school does not consider the technologies with prospects for a quality education.
\end{abstract}

Keywords: Technologies. Media. Education. Learning. Education 


\section{INTRODUÇÃO}

O presente artigo é resultado de um estudo de pós-graduação que tratou da “A importância das novas tecnologias no processo de ensino e aprendizagem". O estudo foi desenvolvido no Programa de Pós-Graduação em Ciências da Educação da Universidad San Carlos (USC), Assunção, Py.

Evidenciou que, apesar de sua importância, são pouco utilizadas em sala de aula como uma ferramenta para auxiliar no processo de ensino aprendizagem. Atualmente percebe-se que as tecnologias estão integradas no cotidiano dos estudantes.

Partiu-se do pressuposto de que o uso das novas tecnologias em sala de aula facilita o envolvimento do educando e melhora sua aprendizagem, além de contribuir significativamente para o desenvolvimento do ensino. Este estudo foi uma oportunidade para analisar a atuação dos professores na utilização das novas tecnologias. Quanto aos professores, devem entender que as novas tecnologias vieram para ficar, e por isso devem atualizar-se e buscar sua própria formação para utilizar os ambientes virtuais como recurso pedagógico.

É sabido que na atualidade há um grande desafio, o educador deverá incorporar as tecnologias para desenvolver um ensino que leve ao aprendizado que tenha sentido para a vida do educando. Será importante incorporar à educação a proposta de Delors (1998), que considera fundamental aprender a conhecer, aprender a fazer aprender a viver juntos e aprender a ser, via essencial que integra os três precedentes.

Também neste estudo, verificou-se a responsabilidade do Estado em relação às lacunas geradas na educação, pois ele investe recursos insuficientes em infraestrutura educacional, remunera com salários baixos os docentes e condiciona a formação dos estudantes aos interesses do mercado.

Optamos por realizar uma pesquisa qualitativa, com trabalho de campo, exploratória e descritiva. E, os principais objetivos deste estudo foram: Refletir sobre a importância da utilização das novas tecnologias no processo de ensino e aprendizagem na escola pública; descrever os tipos de tecnologias e as metodologias utilizadas; averiguar a disponibilidade de tais ferramentas para o uso no processo de ensino e aprendizagem; identificar como se costuma utilizar as novas tecnologias em sala de aula, os obstáculos para a sua utilização e o impacto que o seu uso produz no aprendizado dos estudantes; identificar e analisar os tipos de tecnologias e as metodologias utilizadas; analisar os resultados motivacionais dos estudantes a partir do uso das novas tecnologias; propor a utilização das novas tecnologias como instrumento importante no processo de ensino e aprendizagem. 
Este estudo contribuirá com estudantes e professores, despertando-os para o uso consciente das novas tecnologias. Não se tem como pretensão ditar receitas sobre seu uso, mas somente refletir sobre elas para indicá-las como elemento fundamental na educação.

\section{Os desafios da educação para o uso das novas tecnologias em função do ensino e do aprendizado}

A revolução técnica e científica provocou mudanças, também, na relação escola-aluno, propondo como desafio a inserção das ferramentas midiáticas na educação. Sobre essa nova prática desafiadora para a escola pública, afirmou Fantin (2007, p. 4): “é possível educar integrando mídia e educação [...] fazer educação usando todos os meios tecnológicos disponíveis: computador, internet, celular, fotografia, cinema vídeo, livro, CD, DVD".

É fundamental atentar-se para o fato de que as novas tecnologias, por si só, não são capazes de desenvolver o conhecimento dos educando, mas podem ser facilitadores do aprendizado. Atualmente podem ser utilizadas muitas ferramentas tecnológicas para auxiliar no aprendizado em sala de aula. O vídeo e a TV, por exemplo, são recursos comuns em grande parte das escolas e, com eles, pode-se estimular a linguagem oral e escrita, explorar a capacidade visual e auditiva, porque são recursos que favorecem a motivação dos alunos e o bom relacionamento entre professores e alunos.

A utilização dos recursos midiáticos poderá revolucionar a educação, mas, para isso, será importante que escola e os educadores entendam que "tecnologia de informação e comunicação compreende recursos tecnológicos que envolvem computadores e redes telemáticas (informática + telecomunicação), em especial a rede internet" (SILVA, 2010 p. 7), e que, portanto, deverão estar à disposição dos educadores e também dos alunos para que o processo se desenvolva melhor no sistema educacional. A falta de infraestrutura midiática na escola dificulta a inserção de alunos e professores na sociedade da informação. As novas tecnologias já estão contempladas no Currículo para a educação. Cabe aos gestores públicos inseri-las, com maior eficiência, na rede escolar pública.

É importante destacar que as novas tecnologias, em muitas escolas, ainda não estão acessíveis a todos os estudantes por várias razões: sala de informática com poucos computadores, poucos projetores de imagens, entre outros. Devido à falta de recursos tecnológicos, associada às práticas tradicionais de ensino, os educando não estão sendo preparados para atuarem na sociedade do conhecimento e, em muitas escolas, os alunos continuam sendo formados para provas e vestibulares. Segundo Hargreaves (2004, p.18), a "educação pública é vista como um 
sistema de baixo custo, funcionando a partir de professores pouco qualificados, mal pagos e sobrecarregados, cujo trabalho é manter a ordem, ensinar para as provas e seguir roteiros curriculares padronizados".

Por isso, faz se necessário destinar verbas para a inserção das novas tecnologias em sala de aula. Como se sabe, a realidade das escolas públicas não integrou todos como se pretendia. É necessário superar este modelo, a rede pública estadual de educação vem investindo pouco nessa área, o que torna os recursos insuficientes para que a demanda das escolas seja atendida.

Os educadores devem estar atentos a essa realidade, porque, embora seja uma novidade em termos de metodologia de ensino em sala de aula, é importante entender que os alunos vão para a escola com uma experiência sociocultural e de utilização destes meios tecnológicos que, em muito, pode superar a dos educadores. Como se sabe, outras tecnologias sempre foram utilizadas nas escolas, conforme se afirmou:

A forma como organizamos em grupo, em salas, em outros espaços: isso também é tecnologia. O giz que escreve na lousa é tecnologia de comunicação, e uma boa organização de escrita facilita - muito - a aprendizagem. A forma de falar, gesticular, de falar com os outros: isso também é tecnologia. O livro, a revista, o jornal, o gravador, o retroprojetor, a televisão, o vídeo são tecnologias importantes e muito mal utilizadas em geral. (MORAN, 2003, p.153).

É fundamental que os educadores busquem outras práticas metodológicas, não somente o livro didático, o quadro negro, o giz e as aulas expositivas. Diante desta conjuntura, entende-se que uma melhor qualidade do ensino deverá contar com educadores preparados para a construção de redes interativas. Embora os recursos tecnológicos não estejam tão acessíveis em muitas unidades escolares, não será desculpa negligenciar o uso dos que estão disponíveis.

Poderão ser utilizados, com muita propriedade, aqueles que já fazem parte do acervo escolar como TV, Vídeo, rádio etc. O importante será a busca por desenvolver métodos criativos, para um ensino de qualidade e uma aprendizagem significativa e o oferecimento aos estudantes de oportunidades para que eles se tornem construtores do seu próprio conhecimento. Neste artigo, reflete-se sobre a utilização das novas tecnologias e sobre as ações empreendidas pela escola pública e pelos seus professores para a superação das antigas práticas e a solução dos novos desafios impostos à educação atual.

\section{Caminho metodológico}

É importante ressaltar que essa é uma pesquisa qualitativa, com trabalho de campo, 
exploratória e descritiva. Esta pesquisa foi aprovada pelo Comitê de Ética e Pesquisa (CEP) com o número do protocolo 049/11.

Teve como objetivo investigar as reais dificuldades dos professores no uso das novas tecnologias, na metodologia de ensino, e, também, verificar junto aos estudantes como percebem o uso das tecnologias em sala de aula e qual sua importância. Para realizar esta investigação, optou-se pela pesquisa qualitativa de campo, com teoria fundamentada, pois este caminho metodológico permite entrar em contato direto com fontes científicas. Optamos por esse tipo de abordagem, pois ele tem "como principal fundamento a crença de que existe uma relação dinâmica entre o mundo real, objetivo, concreto e o sujeito; portanto, uma conexão entre a realidade cósmica e o homem, entre a objetividade e a subjetividade" (OLIVEIRA, 2007, p. 60). Essa metodologia possibilitará uma melhor compreensão do objeto estudado e de sua complexidade, "conhecer a realidade vai além de acumular fatos e dados sobre ela. Só a conhecemos se os dados possibilitarem uma compreensão do todo dialético, no qual as partes são compreendidas como 'partes estruturais do todo" (SCHMIDT, 2007, p. 26).

No processo de levantamento de dados, foram entregues questionários a dezesseis professores, de um universo de trinta professores do Ensino Fundamental- II e Ensino Médio. Foi aplicado um questionário aberto para averiguar se os professores utilizam ou não as novas tecnologias em sala de aula e também verificar quais são as tecnologias mais utilizadas e as principais dificuldades na sua utilização.

Para os estudantes foram entregues questionários com o objetivo de averiguar o impacto que o uso das Tecnologias midiáticas causa neles. Participaram da investigação 154 estudantes, num universo de 300 educando do Ensino Fundamental-II e Médio. Foram questões abertas e confirmaram as informações coletadas junto aos professores. Na investigação junto aos alunos, foi utilizado o recurso de mídia para coletar as informações a respeito da utilização das ferramentas em sala de aula.

A seguir, serão apresentados os resultados da averiguação do uso das novas tecnologias como instrumento para promover uma aprendizagem significativa.

\section{Análises dos resultados}

Notou-se nesta escola que os professores dominam e utilizam com frequência as seguintes ferramentas: computadores, projetores de imagens (Data Show), TV, DVD, Rádio, Câmera fotográfica digital e filmadora. Contudo, câmara fotográfica e filmadora são utilizadas eventualmente. Os professores consideraram de suma importância o uso da internet para 
pesquisas. Após o levantamento realizado, constatou-se que os recursos tecnológicos existentes na escola alvo deste estudo, consistem apenas em um Notebook, dois Data Show, duas televisões, dois aparelhos de DVDs e dois rádios.

Em relação à importância das tecnologias no processo de ensino e aprendizagem os professores foram unânimes ao concordar que seu uso é de fundamental importância como se pode notar em seus depoimentos: “"as novas tecnologias despertam nos alunos maior interesse facilitando a aprendizagem”, "“Com as novas tecnologias é possível desenvolver o aprendizado; possibilitam ver as imagens perfeitas, formas e exatidão, é possível analisar, calcular, medir e registrar". Concordamos que os educadores deverão preparar-se melhor para este desafio, pois "com a mediação das ações pelo professor, que deve estar sempre aberto ao diálogo, os estudantes podem produzir conhecimento numa linguagem próxima de sua realidade" (SOUZA, 2011, p.22). É sabido que na sociedade do conhecimento há uma exigência por pessoas com habilidades do pensar, de comunicar-se e trabalhar em equipe. De acordo com Demo (2010) é urgente que os docentes utilizem também em aula os ambientes virtuais de aprendizagem.

Faz se necessária uma didática que inclua os alunos das classes menos favorecidas economicamente na utilização das TICs em função do seu aprendizado. Para Brito (2009) a tecnologia faz parte de nossas vidas e está presente, em toda parte. Isto se confirma no seguinte relato: “"as tecnologias são muito importantes, pois fazem parte do seu cotidiano e ainda tornam as aulas mais interessantes e, se bem utilizadas, podem ser transformadas em habilidades para a aprendizagem de cada individuo". Portanto, o educador deve inserir-se nesse processo, pois "o acesso às novas tecnologias deve ocorrer de forma gradativa, onde o professor possibilite ao aluno inserção às novas tecnologias e, ao mesmo tempo, ir adquirindo conhecimento na sociedade da informação" (SILVA, 2010, p.9).

Também analisamos o que pensam os alunos sobre a utilização das tecnologias em sala de aula e, ainda, a percepção dos estudantes no tocante ao uso destes recursos por parte dos educadores.

Os estudantes foram unânimes em responder que os recursos tecnológicos facilitam compreender o conteúdo. Afirmaram que o computador e o data show facilitam a aprendizagem, pois os professores preparam as aulas utilizando imagens. Segundo eles, podem realizar as pesquisas com maior facilidade e rapidez pela internet. Observaram também que as disciplinas que utilizam as tecnologias possibilitam melhor compreensão do conteúdo, tornando as aulas mais interessantes e participativas. 
Por fim, foi perguntado se preferem as aulas com as novas tecnologias ou as aulas nos moldes tradicionais. Responderam que as preferem com a utilização das novas tecnologias. Em suas respostas afirmaram: "são proveitosas e divertidas", "nós aprendemos mais, parece ficar mais fácil o conteúdo, é mais prático". "O professor não perde muito tempo passando na lousa, ganha tempo explicando o conteúdo, desenvolve mais rápido a aprendizagem, dá a oportunidade de enxergar de maneira diferente o mundo". Por outro lado, consideramos com Almeida (2006) o que está instituído não é somente a "sociedade da informação", mas, sobretudo, a sociedade da aprendizagem.

O resultado da investigação junto aos estudantes confirmou o que a experiência empírica revelou e o que se constatou na análise bibliográfica. E, ainda reforçou o que os professores afirmaram sobre sua prática pedagógica e uso das novas tecnologias.

\section{CONSIDERAÇÕES FINAIS}

Tendo presente a análise realizada ao longo deste trabalho, entendemos ter atingido o objetivo proposto. Percebemos a necessidade de políticas públicas adequadas à educação contemporânea. É necessário que o Estado invista em recursos tecnológicos para a inserção dos estudantes na sociedade do conhecimento. Verificamos que alguns professores têm dificuldades em utilizar as ferramentas tecnológicas por encontrarem-se despreparados e não terem acesso fácil a tais recursos. Segundo Hargreaves (2004) a educação pública encontra-se defasada por serem realizados investimentos de baixo custo. E, ainda, conforme constatamos pela baixa qualificação dos professores para usá-las. Apesar das dificuldades, muitos professores da escola investigada utilizam recursos tecnológicos.

Para reafirmar a importância do uso das novas tecnologias em sala, na pesquisa de campo, junto aos estudantes, pôde-se observar que a maioria deles prefere que os professores utilizem os recursos tecnológicos em sala. Constatamos com este estudo que as disciplinas que se utilizam das novas tecnologias possibilitam melhor compreensão do conteúdo, provocam o interesse e estimulam a curiosidade. Enfatizamos ainda que os meios tecnológicos tornam as aulas participativas, principalmente quando bem explorado pelos professores.

\section{REFERÊNCIAS}

ALMEIDA. M. E.B: Formação e prática pedagógica. São Paulo: Ed. Articulação, 2006. 
BRITO, A. C. A. G. et al. Um Olhar sobre Educação: uma abordagem a partir das novas tecnologias. In: Revista Digital Pandora Brasil no 9. $2009 . \quad$ ISSN 2175-3318. <http://revistapandora.sites.uol.com.br/edicao9.htm> Acesso em: 15 nov. 2010.

DELORS, J. et al. Educação: um tesouro a descobrir. <http://www.dominiopublico.gov.br/downlood/texto/ue000009.pdf> Acesso em: 12 fev. 2010.

DEMO, P. Novas Tecnologias em Educação. In: APASE, Ano XI n 26 - outubro de 2010, p. 5-6.

FANTIN, M. Alfabetização Midiática na Escola. VII Seminário Mídia, educação e Leitura. 10 a13 de Julho. Campinas, SP, 2007.

<http://www.alb.com.br/anais16/sem05pdf/sm05ss15 06.pdf> Acesso em: 10 nov. 2010.

HARGREAVES, Andy. 0 ensino na sociedade de conhecimento: educação na era da insegurança. Porto Alegre: Artmed, 2004.

MORAN, J. M. RELATOS DE EXPERIÊNCIAS Como utilizar a Internet na educação. In:

<http://dx.doi.org/10.1590/S0100-19651997000200006> Ci. Inf. v. 26 n. 2, Brasília, DF., May/Aug. 1997. Acesso em: 7 abr. 2012

OLIVEIRA, M. M. Como fazer Pesquisa Qualitativa. Petrópolis, RJ: Vozes, 2007.

SCHMIDIT, D. P. Violência como uma Expressão da questão Social: suas manifestações e seu enfrentamento no espaço escolar. Dissertação de Mestrado: Santa Maria, RS., Brasil, 2007. In: <http://cascavel.cpd.ufs.br/tde busca/arquivo.pdp?codarquivo=1878> Acesso em: 8 jul. 2010.

SILVA, J. D. Tecnologia e educação: artefatos tecnológicos na dependência de mediadores transformadores. In: APASE, Ano XI no 26 - outubro de 2010, p. 7-10.

SOUZA. R. P. Filomena et. al. Tecnologias digitais na educação. Campina grande: EDUEPB, 2011. 